\title{
Synthesis of $\alpha$-Naphthol and 2,4,7-Trimethyl-Quinolin-5-ol by Using Manganese (III) Acetate and Analysis of Its Antimicrobial Properties
}

\author{
Gülderen Uysal Akkuş \\ Department of Chemistry, Faculty of Art and Science, Afyon Kocatepe University, Afyonkarahisar, Turkey \\ Email:guakkus@gmail.com
}

Received 7 February 2016; accepted 11 March 2016; published 15 March 2016

Copyright (C) 2016 by author and Scientific Research Publishing Inc.

This work is licensed under the Creative Commons Attribution International License (CC BY).

http://creativecommons.org/licenses/by/4.0/

(c) (i) Open Access

\section{Abstract}

This study involves the aromatization reactions of some ketone derivatives through Manganese (III) acetate. The ketone derivatives used in the study are $\alpha$-tetralone (1a), 2,4,7-trimethyl-7,8dihydro quinolinone (1b). At the end of the aromatization reactions of these ketone derivatives the synthesized structures of $\alpha$-naphthol (2a), 2,4,7-trimethylquinoline-5-ol (2b) were identified by spectroscopic methods such as IR, ${ }^{1} \mathrm{H}-\mathrm{NMR},{ }^{13} \mathrm{C}-\mathrm{NMR}$, FAB-MS respectively. Micro-organism types such as Escherichia coli, ATCC 25922, Klepsiella pneumoniae, Staphylococcus aureus NRRL B767, Salmonella typhimurium NRRLB 4420, Bacillus subtilis NRS 744, Bacillus cereus ATCC 11778, Micrococcus luteus ATCC-9341, Listeria monoaytopenus ATCC-7644 bacteria and yeast fungus Candida albicans were used to study the anti-microbial properties of the synthesized $2 b$ compound. The obtained results have determined that compound number $2 b$ has a good antibacterial impact on Bacillus subtilis (NRS-744).

\section{Keywords}

Manganese (III) Acetate, Biological Activity, Radical Reaction, Aromatic, Ketone

\section{Introduction}

Major developments have taken place in the area of reactions with free radicals during recent years in parallel with the developments in technology and laboratory tools and equipment. The present usage area of free radicals has expanded rather comprehensively. This is why there has been a significant increase in the number of scientific 
studies involving free radicals [1]-[4]. The main usage areas are organic chemistry, polymer chemistry and the chemistry of complex natural products. This usage will be observed in more comprehensive areas in the near future. According to the recent studies carried out in the area of radicality it has emerged that the use of radicals can be controlled [5]-[8]. These results encourage chemists to study free radicals in a more accurate and controlled way.

The most widely used transition metal complexes in studies are $\mathrm{Mn}(\mathrm{OAc})_{3}, \mathrm{Cu}(\mathrm{OAc})_{2}, \mathrm{~Pb}(\mathrm{OAc})_{4}, \mathrm{Fe}\left(\mathrm{ClO}_{4}\right)_{3}$. The free radical reactions catalyzed by these complexes are among the most notable reactions. The similarity in reactivity in spite of the fundamental differences in the structures of these metal complexes is noteworthy. These results show that the mechanism and method of the realized reactions are the same. Among them $\mathrm{Mn}(\mathrm{OAc})_{3}$ is the most frequently used catalyst in free radical chemistry. The reason for this is that $\mathrm{Mn}(\mathrm{OAc})_{3}$ has a moderate degree of reactivity and a high degree of selectivity.

Particularly from the end of the 1960 's to date $\mathrm{Mn}(\mathrm{OAc})_{3}$, various carbonyl compounds such as $\beta$-diketones, acetoacetamides, $\beta$-keto esters, acyl acetonitriles, mercapto ketones are used widely to establish carbon centered radicals [9]-[13].

The initial studies carried out with Manganese (III) acetate involved the generation of lactone and dilactone from alkenes, the oxidation of substituted aromatic compounds and addition reactions. In subsequent years the radical cyclization reactions between $\mathrm{Mn}$ (III) and the alkenes of 1,3-dioxo compounds (malonic ester, acetylacetone, etc.) have been studied in detail. Furthermore the addition-cyclization reactions of enolizable 1,3-dicarbonile compounds through Manganese (III) acetate have been studied [14]-[20].

No studies carried out with $\mathrm{Mn}(\mathrm{OAc})_{3}$ for the aromatization of tetralones have been encountered in a review of previous studies in literature. Therefore, the aromatization of $\mathrm{Mn}(\mathrm{OAc})_{3}$ with some ketone derivatives was carried out to synthesize 1-naphthol, 6-methoxy-1-naphthol and 2,4,7-trimethyl quinolinole compounds. Furthermore the biological activity properties of the synthesized compounds were tested.

\section{Experimental}

\subsection{Materials}

A Gallenkamp brand melting point tester was used to determine the melting point. ${ }^{1} \mathrm{H}$ NMR spectrums with $\mathrm{CDCl}_{3}$ were obtained with Bruker DPX $400 \mathrm{MHz}$ spectrophotometer and TMS was used as a standard. Chemical shift values $(\delta)$ in the NMR spectrum were indicated as ppm. IR spectrums were obtained from the Perkin Elmer 1605 FTIR System Spectrum BX spectrophotometer in the form of $\mathrm{KBr}$ discs. Element analyses were executed with Elementar CHNS apparatus. The mass spectrums (FAB-MS $\mathrm{m} / \mathrm{z}$ ) of the compounds were taken with a Varian MAT 312 brand spectrometer.

Thin layer chromatography (TLC) was carried out by using aluminum plates coated with a silica gel layer $\left(\mathrm{SiO}_{2}\right.$, Merck $\left.60 \mathrm{~F}_{254}\right)$. Silica gel 60 (Merck, particle size $(60-43 \mu \mathrm{m})$ was used in column chromatography studies. All chemical reactive substances were of a commercial purity and obtained ready for use from Merck or Fluka.

All microorganism strains were obtained from the Culture Collection of Microbiology Laboratory of Afyon Kocatepe University, Afyonkarahisar, Turkey.

\subsection{Synthesis}

\subsubsection{Synthesis of Compound 2a}

A double necked $250 \mathrm{ml}$ flask with a fitted dean stark apparatus is filled with a mixture of $\mathrm{KMnO}_{4}(3 \mathrm{mmol}$; $0.474 \mathrm{~g}) 100 \mathrm{~mL}$ benzene-acetic acid (10:1) solution. The solution is boiled in a condenser until the $\mathrm{KMnO}_{4}$ which is purple turns brown. At the end of this process the reaction mixture is evaporated to remove the benzene. $\alpha$-tetralon ( $1 \mathrm{mmol} ; 0.146 \mathrm{~g}$ ) is added onto the Manganese(III)acetate remaining in the reaction flask and the flask is fitted with the condenser and boiled. The reaction is monitored with TLC and the boiling procedure continues until the initial substance is completely gone. When the initial substance has transformed completely into a product the reaction is halted and cooled until ambient temperature is achieved. Subsequently the reaction mixture is diluted with ether and neutralized with $\mathrm{NaHCO}_{3}$. The separated organic phases are combined and dried with anhydrous $\mathrm{Na}_{2} \mathrm{SO}_{4}$ and concentrated under vacuum. The crude product is purified with a flash chromatograph (hexane: ethyl acetate). Yield: 0.12 g (85\%), E.n: $91^{\circ} \mathrm{C}-92^{\circ} \mathrm{C}$. IR: $3340 \mathrm{~cm}^{-1}(\mathrm{OH}) .{ }^{1} \mathrm{H}$ NMR 
$\left(\mathrm{CDCl}_{3}\right): \delta 5.42$ (br s, $\left.1 \mathrm{H}, \mathrm{OH}\right), 6.82(\mathrm{~d}, 1 \mathrm{H}, J=7.4 \mathrm{~Hz}, \mathrm{CH}), 7.34$ (t, 1H, $\left.J=7.4 \mathrm{~Hz}, \mathrm{CH}\right), 7.48-7.61$ (m, 3H, $\mathrm{CH}), 7.85$ - $7.91(\mathrm{~m}, 1 \mathrm{H}, \mathrm{CH}), 8.22$ - $8.25(\mathrm{~m}, 1 \mathrm{H}, \mathrm{CH}) .{ }^{13} \mathrm{C}$ NMR $\left(\mathrm{CDCl}_{3}\right), \delta(\mathrm{ppm}): 120.7,121.4,124.3,125.3$, 125.8, 126.4, 127.6, 134.7, 151.2. FAB-MS m/z: $145.06[\mathrm{M}+\mathrm{H}]^{+}$. Anal. Calculated C, 83.31; H, 5.59. Found: C, 79.03; H, 5.22 .

\subsubsection{Synthesis of Compound $2 \mathrm{~b}$}

A double necked $250 \mathrm{ml}$ flask with a fitted dean stark apparatus is filled with a mixture of $\mathrm{KMnO}_{4}(3 \mathrm{mmol}$; $0.474 \mathrm{~g}) 100 \mathrm{~mL}$ benzene-acetic acid (10:1) solution. The solution is boiled in a condenser until the $\mathrm{KMnO}_{4}$ which is purple turns brown. At the end of this process the reaction mixture is put into an evaporator to remove the benzene. 2,4,7-trimethyl-7,8-dihydro quinolinone ( $1 \mathrm{mmol}$; $0.189 \mathrm{~g}$ ) is added onto the Manganese (III) acetate remaining in the reaction flask and the flask is fitted with the condenser and boiled. Compound number $2 \mathrm{c}$ is achieved by the reaction which incurs when the methods and procedures explained above are carried out. Yield: 0.08 g (43\%). E.n: $151^{\circ} \mathrm{C}$. IR: $3420 \mathrm{~cm}^{-1}(\mathrm{OH}) .{ }^{1} \mathrm{H}$ NMR $\left(\mathrm{CDCl}_{3}\right): \delta 2.15$ (s, 3H, $\left.\mathrm{CH}_{3}\right) ; 2.70$ (s, 3H, $\left.\mathrm{CH}_{3}\right) ; 2.93$ (s, 3H, $\left.\mathrm{CH}_{3}\right) ; 6.93-7.22$ (m, 3H, ArH); 8.12 (br s, $\left.1 \mathrm{H}, \mathrm{OH}\right) .{ }^{13} \mathrm{C}$ NMR $\left(\mathrm{CDCl}_{3}\right), \delta(\mathrm{ppm}): 20.2,24.6,104.4$, 113.6, 121.2, 136.3, 138.3, 147.3, 152.7, 159.7. FAB-MS m/z: $188.10[\mathrm{M}+\mathrm{H}]^{+}$. Anal. Calculated $\mathrm{C}_{12} \mathrm{H}_{13} \mathrm{NO}$ (187.10): C, 76.98; H, 7.00; N, 7.48. Found: C, 75.53; H, 6.32, N, 7.02.

\subsection{Antimicrobial and Antifungal Effects Studies}

\subsubsection{Chemicals and Microbial Test Strains}

Compound $2 \mathrm{~b}$ prepared as a $50 \%(\mathrm{w} / \mathrm{v})$ stock solution chloroform, the resulting solution was passed through the membrane filters for the separation of particulate structures. A number of fungal and bacterial isolates were kindly obtained from Afyon Kocatepe University, Faculty of Molecular Biology and Genetics Department. The hospital isolates of bacteria were identified by Phonix BD automatic identification system (Phoenix, BD, USA) [21]. These bacteria were used to determine the anti-microbial activity.

\subsubsection{Staining and Observation}

Escherichia coli ATCC 25922, Klebsiella pneumoniae, Pseudomonas aeruginosa, Staphylococcus aureus NRRL-B 767, Salmonella typhimurium, Bacillus cereus ATCC 11778, Bacillus subtilis NRS 744 bacteriums and Maya candida fungus were developed within NA (Nutrient agar). Microscope observations were made using a Nikon Eclipse E200 microscope.

\subsubsection{Determination of Antimicrobial Activity}

The antibacterial activity of Compoun 2b was assessed against bacteria species: Escherichia coli ATCC 25922, Klebsiella pneumoniae, Pseudomonas aeruginosa, Staphylococcus aureus NRRL-B 767, Salmonella typhimurium, Bacillus cereus ATCC 11778, Bacillus subtilis NRS 744 bacteriums and Maya candida fungus. Antimicrobial activity was determined by using disc diffusion method [22]. Solvent was used as negative control. Ceftriaxone was used as positive controls. All tests were repeated in triplicater. Bacterial isolates were grown in Mueller-Hinton broth for 24 hours, swabbed evenly onto the surface of Mueller-Hinton agar using sterile cotton swabs, and allowed to dry. Impregnated filter paper disks (100 $\mu \mathrm{L})$ (Difco) placed on the surface of each plate for each isolate and then incubated at $37^{\circ} \mathrm{C}$ for 24 hours. Inhibition zones were then measured to the nearest millimeter. Inhibition zones were indicated by a lack of microbial growth due to inhibitory [23].

\section{Results and Discussion}

In recent years many studies have been carried out in which Manganese (III) acetate is used as a catalyzer. Some of the studies on this issue are summarized as follows:

Yllmaz et al. (2012) interacted 1,3-dicarbonyl compounds with cyclic and non-cyclic structures with substituted conjugated alkenes in an environment of $\mathrm{Mn}(\mathrm{OAc}) 3 / \mathrm{AcOH}$ and synthesized 4,5-dihydrofurans with good yields [18].

Yuan et al. (2011) used 1,3-dicarbonyl compounds and substituted vinyl cyclopropane manganese (III) acetate oxidative cyclization reaction to synthesize appropriate functional dihydrofuran derivatives [24].

In a study carried out by Biermann, U. et al. (2013) the reaction of adding azitin radicality to the $\mathrm{C}=\mathrm{C}$ double bonds of unsaturated fatty acids such as methyl oleate and methyl 10-undecanoate in a manganese (III) acetate 
medium was studied [19].

Lopchuk et al. (2013) studied the addition of radicality into methylene and methylene compounds activated by a manganese (III) acetate medium with 2-cyanoindole and N-methyl-2-cyanoindole compounds. Subsequently these compounds were subjected to an additional oxidation reaction and their structures were irradiated with x-ray crystallography method [25].

In their study Demir et al. (2010) synthesized biphenyl and biphenyl compounds of a hetero structure producing high yield with the microwave method in a Manganese (III) acetate medium by exiting aryl bocacic acid [26].

Yllmaz and Pekel (2005) carried out a study in which the reactions of $\beta$-diketones with branched alkenes in a manganese (III) acetate medium were studied and the results are displayed in table 2.3. Although dihydrofurans were obtained from 1,2-diphenyl substituted alkenes with low yields it is evident that 1,1-diphenyl substituted alkenes provided dihydrofurans with rather high yields [27].

Haque and Nishino (2012) carried out a study conducted in temperate conditions to study the direct oxidation reactions of 3-alkyl-substituted 2,4-pyrrolidones using manganese (III) acetate. This reaction provided 3-hydroperoxy pyrrolidine-2,4-diones with quantitative yield [28].

Referring to previous studies carried out with Manganese (III) acetate it is apparent that there are two substituents in the reaction and that as a catalyst manganese (III) acetate appears to accelerate the reaction. A comparison of this study with previous studies reveals that the difference between the studies is that in this study the manganese (III) acetate is incorporated directly into the ketone compound and the structure is transformed into an aromatic state which is more stable.

Ketone derivatives $\alpha$-tetralone (1a), 2,4,7-trimethyl-7,8-dihydro quinolinone (1b) were used for this purpose (Figure 1). The reaction mechanism is given schematically in Figure 2.<smiles>O=C1CCCc2ccccc21</smiles>

$1 \mathbf{a}$<smiles>Cc1cc(C)c2c(n1)CC(C)CC2=O</smiles>

$1 \mathbf{b}$

Figure 1. Ketone derivatives used in a Mn(III)acetate medium in aromatization reactions.

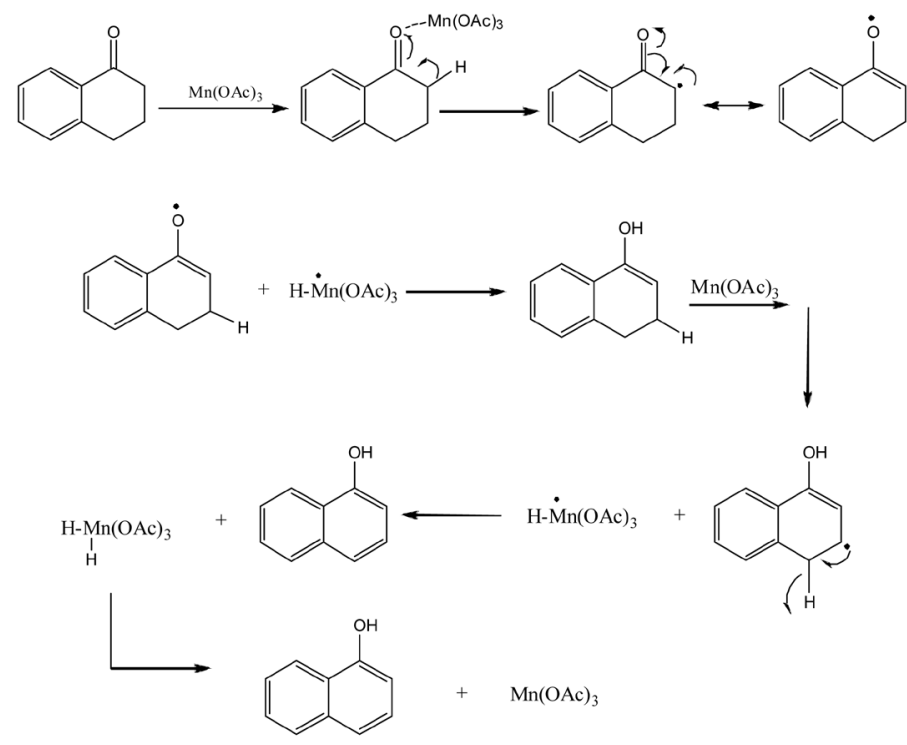

Figure 2. The aromatization reaction mechanism of ketones in the medium manganese (III) acetate. 


\subsection{Synthesis}

In the synthesis phase of the study manganese (III) acetate was obtained for the time according to literature [29]. $\mathrm{KMnO}_{4}$ was diluted in acetic acid-benzene for this. Subsequently the solution was boiled under a dean stark apparatus until the purple color of potassium permanganate turned brown. Benzene was removed under reduced pressure from the cooled reaction mixture after which $1 \mathrm{mmol}$ of $\alpha$-tetralone was added without any further purification to the flask. A condenser was attached to the flask and boiling was resumed.

The reaction was monitored with thin layer chromatography. The boiling procedure was continued under the condenser until the initial material had disappeared completely. When the initial material had disappeared completely the reaction mixture was cooled to room temperature, diethyl ether was added and the mixture was neutralized with $\mathrm{NaHCO}_{3}$. The resulting crude product hexane: $\alpha$-naphthol (2a) was obtained by purification with a flash chromatography in an ethyl acetate medium.

Compound $2 \mathrm{a}$ was obtained with $0.12 \mathrm{~g}$ (with $85 \%$ yield). Melting point $91^{\circ} \mathrm{C}-92^{\circ} \mathrm{C}$. ${ }^{1} \mathrm{H}$ NMR spectrum results are interpreted as follows; broad singlet peak in $5.42 \mathrm{ppm}$ reveals the presence of an $\mathrm{OH}$ group in the structure. The peaks observed in the 6.82, 7.34, 7.48, 7.85, $8.22 \mathrm{ppm}$ zones belong to the aromatic protons in the structure. Out of the IR spectrum results of the compound a broad band in $3340 \mathrm{~cm}^{-1}$ band displays the presence of an $\mathrm{OH}$ group in the structure. Furthermore the absence of a peak in zone $1720 \mathrm{~cm}^{-1}$ indicates that the $\mathrm{C}=\mathrm{O}$ group belonging to the ketone group is absent which provides the most important proof that a reaction had taken place.

The synthesis of 2,4,7-dimethyl quinoline-5-ol (2b) compound was carried out according to the method mentioned above. Accordingly, manganese (III) acetate was obtained after $\mathrm{KMnO}_{4}$ was dissolved in acetic acid-benzene and boiled under the condenser device fitted with a dean-start apparatus. Subsequently $1 \mathrm{mmol}$ of 2,4,7-trimethyl 7,8-dihydro quinolinone (1b) was added and the boiling was continued under the condenser. In accordance with the method explained above the reaction mixture was cooled to room temperature, diethyl ether was added and the mixture was neutralized with $\mathrm{NaHCO}_{3}$. The resulting crude product hexane: 2,4,7-trimethylquinoline-5-ol (2b) was synthesized by purification in a flash chromatography in an ethyl acetate medium with a yield of $43 \%$.

The ${ }^{1} \mathrm{H}$ NMR spectrum results for compound $2 \mathrm{~b}$ are as follows; the singlet peaks in 2.15, 2.70, $2.93 \mathrm{ppm}$ belong to the $\mathrm{CH}_{3}$ groups in the structure. The multiple peaks in the $6.93-7.22 \mathrm{ppm}$ zone belong to the aromatic protons in the structure. The formation of an $\mathrm{OH}$ group was revealed by the broad band in $3420 \mathrm{~cm}^{-1}$ in the IR spectrum results of the compound as was the case for the first compound. At the same time the absence of a band around $1720 \mathrm{~cm}^{-1}$ belonging to the $\mathrm{C}=\mathrm{O}$ group indicates that the ketone group in the structure has disappeared and that a reaction has occurred.

The synthesized compounds and the yield \% and the reaction times are presented in a table (Table 1).

\subsection{Study of Antibacterial and Antifungal Properties}

The 2,4,7-dimethyl quinoline-5-ol (2b) obtained in this study determined whether the compound had antibiotic properties in terms of various microorganisms. Micro-organism types Escherichia coli ATCC 25922, Klepsiella pneumoniae, Staphylococcus aureus MRRL B767, Pseudomanas aeruginosa, Salmonella typhimurium NRRLB 4420, Bacillus subtilis NRS 744, Bacillus cereus ATCC 11778 bacteria which are very common and Maya candida albicans fungus were used.

Disk diffusion method was used to measure the antimicrobial property of the compound. To do this empty sterile $6 \mathrm{~mm}$ diameter disks were absorbed with the saturated solution of compound $\mathbf{2 b}(25 \mu \mathrm{L})$. The bacterial cultures were left to incubate at $37^{\circ} \mathrm{C}$. Subsequently the bacterial suspensions were inoculated with sterile cotton swabs into petri dishes with an agar medium. After the cultivation of the bacteria the prepared disks were placed on the surface of the medium. They were kept at room temperature for half an hour and subsequently incubated at $37^{\circ} \mathrm{C}$ for 24 hours. If the compound is toxic microbial development around the sample will be inhibited and the reproduction of the micro-organisms is halted and zones will be formed. The width of these zones established by diffusion are indicators of the antibacterial or antifungal impact of the sample [22]. The diameters of these zones have been measured with a ruler at the end of the growth period and are given in a table [23] (Table 2).

According to the results produced by antimicrobial studies; it was determined that in comparison with standard drugs such as Ceftriaxone (CRO) compound $\mathbf{2 b}$ had an antimicrobial affect on all G(-) bacteria. The highest 
Table 1. Substituted 1-naphthol and 2,4,7-trimethyl quinoline-5-ol compounds.

Time (hours)

Table 2. Antimicrobial impact of compound $\mathbf{2 b}$ (zone diameters, mm).

\begin{tabular}{|c|c|c|c|}
\hline Micro-organism & $\begin{array}{l}\text { Negative Control } \\
\text { (Chloroform) }\end{array}$ & $\begin{array}{l}\text { Positive Control } \\
\text { CRO (mm) }\end{array}$ & $\begin{array}{c}\text { Compound 2b } \\
(25 \mu \mathrm{L})\end{array}$ \\
\hline \multicolumn{4}{|l|}{ Gram (-) } \\
\hline Salmonella typhimurium (NRRLB-4420) & 7 & 15 & 12 \\
\hline Klepsiella pneumonia & - & 21 & 10 \\
\hline Escherichia coli (ATCC-25922) & - & 16 & 7 \\
\hline Proteus vulgaris & 10 & ND & 10 \\
\hline \multicolumn{4}{|l|}{ Gram $(+)$} \\
\hline Bacillus cereus (ATCC-11778) & 12 & 8 & 12 \\
\hline Bacillus subtilis (NRS-744) & 13 & 8 & 19 \\
\hline Stapylococus aureus (NRRL-B 767) & 7 & 30 & 17 \\
\hline Micrococcus luteus (ATCC-9341) & 10 & - & 13 \\
\hline Listeria monoaytopenus (ATCC-7644) & - & 21 & 10 \\
\hline \multicolumn{4}{|l|}{ Yeast } \\
\hline Candida albicans & - & ND & 11 \\
\hline
\end{tabular}

Compound concentrates: $25 \mu \mathrm{L} /$ disk; (-) sign indicates that the compounds have no impact against micro-organisms. Ceftriaxone (CRO) was used as a positive control, ND: not determined.

impact was observed with Salmonella typhimurium (NRRLB-4420) with $12 \mathrm{~mm}$. This was followed by Klepsiella pneumoniae and Proteus vulgaris with $10 \mathrm{~mm}$. Similarly this compound had a microbial impact on G(+) bacteria. The highest microbial impact among the tested micro-organisms was observed with Bacillus subtilis (NRS-744) (19 mm) and this was followed by Stapylococus aureus (NRRL-B 767) with 17 mm, Micrococcus luteus (ATCC-9341) with $13 \mathrm{~mm}$ and Listeria monoaytopenus (ATCC-7644) with $10 \mathrm{~mm}$. It was observed that this compound had an antimicrobial impact on Candida albicans which is a type of fungus. According to these achieved results it can be asserted that this compound generates a biological activity on both bacteria as well as yeasts. In conclusion it can be asserted that compound $\mathbf{2 b}$ can be used in antibiotic studies against many bacteria.

\section{Acknowledgements}

I gratefully acknowledge the financial support of Afyon Kocatepe University Research Fund (Project No: 12.FENED.03). I also express my thanks to Dr. S. Elif Korcan from Molecular Biology and Genetics Department for biological activity studies. 


\section{References}

[1] Curran, D.P. (1988) The Design and Application of Free Radical Chain Reactions in Organic Synthesis. Part I. Synthesis, 6, 417-439. http://dx.doi.org/10.1055/s-1988-27600

[2] Iqbal, J., Bhatia, B. and Nayyar, N.K. (1994) Transition Metal-Promoted Free-Radical Reactions in Organic Synthesis: The Formation of Carbon-Carbon Bonds. Chemical Reviews, 94, 519-564. http://dx.doi.org/10.1021/cr00026a008

[3] Fossey, J., Lefort, D. and Sorba, J. (1996) Free Radicals in Organic Chemistry J. Am. Chem. Soc. 1996, $118,4226$. Journal of the American Chemical Society, 118, 10678-10678. http://dx.doi.org/10.1021/ja9654490

[4] Brand-Williams, W., Cuvelier, M.E. and Berset, C.L.W.T. (1995) Use of a Free Radical Method to Evaluate Antioxidant Activity. LWT-Food Science and Technology, 28, 25-30. http://dx.doi.org/10.1016/S0023-6438(95)80008-5

[5] Godula, K. and Sames, D. (2006) CH Bond Functionalization in Complex Organic Synthesis. Science, 312, 67-72. http://dx.doi.org/10.1126/science.1114731

[6] Sibi, M.P. and Porter, N.A. (1999) Enantioselective Free Radical Reactions. Accounts of Chemical Research, 32, 163171. http://dx.doi.org/10.1021/ar9600547

[7] Recupero, F. and Punta, C. (2007) Free Radical Functionalization of Organic Compounds Catalyzed by N-Hydroxyphthalimide. Chemical Reviews, 107, 3800-3842. http://dx.doi.org/10.1021/cr040170k

[8] Mondal, M. and Bora, U. (2013) Recent Advances in Manganese (iii) Acetate Mediated Organic Synthesis. RSC Advances, 3, 18716-18754. http://dx.doi.org/10.1039/c3ra42480d

[9] Yan, G., Yang, M. and Wu, X. (2013) Synthetic Applications of Arylboronic Acid via an Aryl Radical Transfer Pathway. Organic and Biomolecular Chemistry, 11, 7999-800. http://dx.doi.org/10.1039/c3ob41851k

[10] Fisher, H.C., Berger, O., Gelat, F. and Montchamp, J.L. (2014) Manganese-Catalyzed and Promoted Reactions of H-Phosphinate Esters. Advanced Synthesis and Catalysis, 356, 1199-1204. http://dx.doi.org/10.1002/adsc.201301157

[11] Chany, A.C., Marx, L.B. and Burton, J.W. (2015) Synthesis of Bicyclic Tetrahydrofurans from Linear Precursors Using Manganese (iii) Acetate. Organic and Biomolecular Chemistry, 13, 9190-9193. http://dx.doi.org/10.1039/C5OB01091H

[12] Li, P., Zhao, J., Xia, C. and Li, F. (2014) Direct Oxidative Coupling of Enamides and 1,3-Dicarbonyl Compounds: A Facile and Versatile Approach to Dihydrofurans, Furans, Pyrroles, and Dicarbonyl Enamides. Organic Letters, 16, 5992-5995. http://dx.doi.org/10.1021/ol503009f

[13] Matsumoto, R. and Nishino, H. (2015) Advanced Synthesis of Dihydrofurans: Effect of Formic Acid on the Mn (III)Based Oxidation. Synthetic Communications, 45, 1807-1816. http://dx.doi.org/10.1080/00397911.2015.1049618

[14] Alagöz, O., Yılmaz, M., Pekel, A.T., Graiff, C. and Maggi, R. (2014) Synthesis of Dihydrofuro- and C-Alkenylated Naphthoquinones Catalyzed by Manganese (III) Acetate. RSC Advances, 4, 14644-14654. http://dx.doi.org/10.1039/c3ra48015a

[15] Dey, S.K. and Mukherjee, A. (2014) Manganese (III) Acetate Mediated Catalytic Oxidation of Substituted Dioxolene and Phenols. Journal of Molecular Catalysis A: Chemical, 395, 186-194. http://dx.doi.org/10.1016/j.molcata.2014.08.014

[16] Montchamp, J.L. (2014) Carbon-Hydrogen to Carbon-Phosphorus Transformations. In: Phosphorus Chemistry II, Springer International Publishing, 217-252. http://dx.doi.org/10.1007/128_2014_558

[17] Biçer, E. and Yılmaz, M. (2013) Synthesis of Trifluoromethylated Dihydrofurans by Addition of 1, 3-Dicarbonyl Compounds to Alkenes Promoted by Manganese (III) Acetate. Arkivoc, 3, 304-316.

[18] Biçer, E., Yılmaz, M., Karataş, M. and Pekel, A.T. (2012) Radical Cyclization Reactions via Manganese (III) Acetate Leading to 2-Thienyl-Substituted Dihydrofuran Compounds. Helvetica Chimica Acta, 95, 795-804. http://dx.doi.org/10.1002/hlca.201100397

[19] Biermann, U., Linker, U. and Metzger, J.O. (2013) Manganese (III) Acetate Induced Radical Addition of Azide to Unsaturated Fatty Compounds. European Journal of Lipid Science and Technology, 115, 94-100. http://dx.doi.org/10.1002/ejlt.201200228

[20] Bouhlel, A., Curti, C., Tabele, C. and Vanelle, P. (2013) Manganese (III) Acetate-Mediated Oxidative Cyclization of a-Methylstyrene and Trans-Stilbene with $\beta$-Ketosulfones. Molecules, 18, 4293-4307. http://dx.doi.org/10.3390/molecules18044293

[21] Williams, W., Dunk, T., Landerkin, K., Smith, E., White, V., Salomon, J. and Reuben, J. (2005) Accuracy of Identification in BD Phoenix ${ }^{\mathrm{TM}}$ Using the New Low Inoculum Mode. As presented at the 105th General Meeting of the American Society for Microbiology. https://www.bd.com/ds/technicalCenter/whitepapers/lr884.pdf

[22] Bauer, A.W., Kirby, W.M.M., Sherris, J.C. and Turck, M. (1966) Antibiotic Susceptibility Testing by a Standardized Single Disk Method. American Journal of Clinical Pathology, 45, 493. 
[23] Uysal Akkus, G., Al, E. and Korcan, S.E. (2015) Selective Extraction of Toxic Heavy Metals and Biological Activity Studies Using Pyrimidylthioamide Functionalised Calix[4]arene. Supramolecular Chemistry, 27, 522-526. http://dx.doi.org/10.1080/10610278.2015.1020944

[24] Yuan, W., Wei, Y. and Shi, M. (2011) Manganese (III)-Mediated Oxidative Annulation of Vinylidenecyclopropanes with 1,3-Dicarbonyl Compounds. Tetrahedron, 67, 7139-7142. http://dx.doi.org/10.1016/j.tet.2011.06.109

[25] Lopchuk, J.M., Montgomery, W.L., Jasinski, J.P., Gorjifard, S. and Gribble, G.W. (2013) Manganese (III)-Mediated Oxidative Radical Addition of Malonates to 2-Cyanoindoles. Tetrahedron Letters, 54, 6142-6145. http://dx.doi.org/10.1016/j.tetlet.2013.09.012

[26] Demir, A.S., Findik, H., Saygili, N. and Subasi, T.N. (2010) Manganese (III) Acetate-Mediated Synthesis of Biaryls under Microwave Irradiation. Tetrahedron, 66, 1308-1312. http://dx.doi.org/10.1016/j.tet.2009.12.018

[27] Yilmaz, M. and Pekel, A.T. (2005) Manganese (III) Acetate Mediated Synthesis of 3-Trifluoroacetyl-4, 5-Dihydrofurans and 3-(Dihydrofuran-2(3H)-ylidene)-1,1,1-trifluoroacetones by Free Radical Cyclization. Part 1. Journal of Fluorine Chemistry, 126, 401-406. http://dx.doi.org/10.1016/j.jfluchem.2005.02.002

[28] Haque, M.A. and Nishino, H. (2012) Facile Access to 3-Alkyl-Substituted 3-Hydroperoxy-2,4-pyrrolidinediones Using Manganese (III)-Catalyzed Aerobic Oxidation. Synthetic Communications, 42, 608-619. http://dx.doi.org/10.1080/00397911.2010.528129

[29] Demir, A.S. and Findik, H. (2008) Potassium Permanganate/Carboxylic Acid/Organic Solvent: A Powerful Reagent for Enone Oxidation and Aryl Coupling Reactions. Tetrahedron, 64, 6196-6201.

http://dx.doi.org/10.1016/j.tet.2008.05.004 